\title{
Teknologi Hijau Warisan Nenek Moyang di Tanah Parahyangan
}

\author{
Handajani Asriningpuri ${ }^{1}$, Fajar Kurniawati ${ }^{2}$, Galih Pambudi ${ }^{3}$ \\ 1,2,3 Institut Teknologi Indonesia - Jl Raya Puspiptek Muncul - Serpong, Tangerang Selatan, Banten \\ Email: 1,2,3 hasriningpuri@yahoo.com;niafknw@gmail.com; pambudigalih@ rocketmail.com
}

\begin{abstract}
Abstrak
Masyarakat tradisional umumnya tidak berkebutuhan majemuk; sederhana; bersahaja; dan menerima keberadaan alam sebagai sahabat, bahkan merupakan bagian kehidupannya. Keadaan ini terjadi di Kampung Naga, Garut, Tanah Parahyangan sebagai suatu kearifan lokal. Dari sudut pandang arsitektur, hal tersebut menginspirasi konsep perancangan.

Penelitian ini, membuktikan dari sudut pandang ilmu lingkungan dan arsitektur tentang adanya kaitan kearifan lokal dengan teknologi hijau yang menerapkan "green concept"(ZEB - Zero Energy Building dan 3R - Reuse, Reduce, Recycle).

Metoda yang dilakukan adalah metoda diskriptif kualitatif berdasarkan data primer dan sekunder hasil observasi lapangan dan literatur. Kemudian dikaji melalui teori Aarsitektur dan pendekatan Teknologi Hijau, dan dibuktikan melalui Greenship Home Assestment (ketentuan GBCI - Green Building Council Indonesia)

Hasil kajian dan temuan pemahaman kearifan lokal, akan menginspirasi, membangkitkan semangat hijau, dan menambah wawasan bagiperancang bangunan. Bagi para regulator (pemerintah daerah) kearifan lokal harus di pertahankan dan dapat menyadarkan penduduk kampung Naga untuk tetap berkehidupan sesuai ketentuan yang di yakini.
\end{abstract}

Kata Kunci : Green Concept, Kampung Naga, Kearifan lokal, Teknologi Arsitektur

\section{LATAR BELAKANG}

Konsep rancang bangun yang bernuansa lokal tidak lagi bertumpu pada kearifan lokal, karena trend bagi perancang lokal agar terlihat "modern" diambil dengan cara mengagungkan dan meniru konsep asing. Kearifan lokal hanya sebagai pelengkap, sementara itu Salura (2007) mengatakan bahwa karya arsitektur tidak pernah lepas dari konteks budaya ditempat arsitektur tersebut berada, jika budaya masyarakat berubah maka arsitektur akan cenderung ikut berubah.Pengetahuan arsitektur lokal harus dipertahankan eksistensinya agar tetap terpelihara sehingga dapat dimanfaatkan sebagai landasan rancang bangun didalam proses disain dan penelitian.

Wilayah Parahyangan terdiri dari Karesidenan Batavia dan Cirebon disisi Utara; Bantendisisi Barat; Samudra Hindia disebelah Baratdaya dan Selatan (Salura, 2007).

Menurut Salura:(2007) didaerah Parahyangan ada 4 kampung adat, yaitu Kampung Kuta di Kab.Ciamis;Kampung Naga di Kab.Garut; Kampung Pulo Kab.Garut; dan Kampung Tonggoh di Selatan Garut.Menurut Dinas Pariwisata Pemerintah Daerah Jawa Barat bidang kebudayaan, Kampung Adat terdiri dari: 1. Kampung Cikondang di Desa Lamajang-Kecamatan Pangalengan Kabupaten Bandung; 2. Kampung Kuta di Desa Karang Paninggal - Kecamatan Tambak Sari, 
Kabupataen Ciamis; 3. Kampung Mahmud di Desa Mekar Rahayu - Kecamatan Marga Asih Kabupaten Bandung; 4. Kampung Sukamulya (Kampung Gede kasepuhan Cipta Gentar) di Desa Sirna Resmi-Kecamatan Cisolok kabupaten Sukabumi; 5. Kampung Dukuh di Desa Cijambe Kecamatan Cilelet Kabupaten Garut; 6. Kampung Nagawir (Naga) di Desa Neglasari-Kecamatan Salawu Kabupaten Garut; 7. Kampung Pulo di Desa Situ Cangkuang - Kecamatan Leles Kabupaten Garut; dan 8. Kampung Urug di Desa Kiara Pandak-Kecamatan Sukajaya Kabupaten Bogor.

Kampung Tonggoh di Desa Cilaut- Kecamatan Pamengpeuk Kabupaten Garut tidak terdata disperbud pemprov Jawa Barat karena lokasinya yang terlalu jauh dari desa terdekat (Cilaut - Kec. Pameungpeuk), selain itu desa ini sangat selektif menerima tamu dan pengaruh dari luar.

Dari kedelapan kampung adat tersebut tidak semuanya terjaga kekuatan adat dan budayanya, hanya ada satu kampung yang masih kuat berpegang pada adat dan budaya yaitu Kampung Nagawir (Kampung Naga) walau lokasinya mudah dicapai namun dalam beradat-istiadat budaya Sunda dan kekuatan memeluk Agama Islam tetap terjaga. Dengan mempertimbangkan keunikan dan mengingat keterbatasan yang ada pada tim, maka objek kajian dipilih Kampung Nagawir (Naga) diwilayah Kampung Legok Dage di Desa Neglasari-Kecamatan Salawu Kabupaten Garut yang mewakili lokasi penerapan Teknologi Hijau yang sampai saat ini tetap terjaga tata kehidupan, bermukim dan bermasyarakat dengan Kearifan Lokal yang unik berada di tanah Parahyangan atau Priangan.

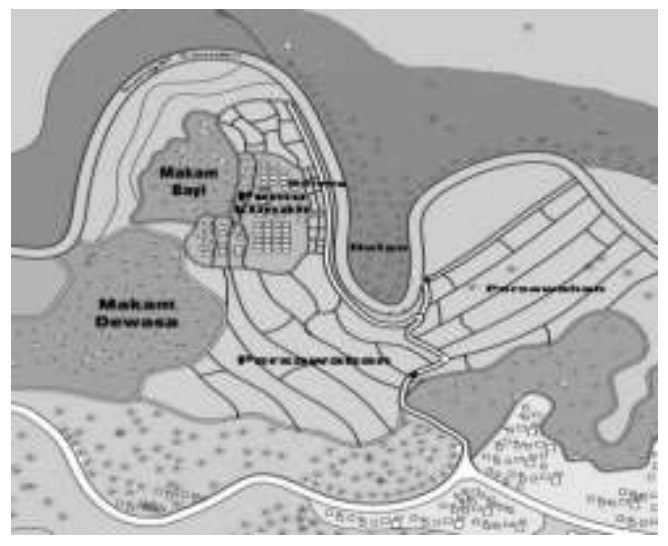

Gambar.1. Site Plan Kampung Naga

(Sumber : Dokumentasi Pribadi)

Teknologi Hijau adalah Teknologi yang mempertimbangkan penghematan dalam penggunaan sumberdaya alam dan menjaga keberlangsungan ketersediaannya serta meminimalisasi dampak negatif bahkan berusaha meningkatkan kualitas hidup manusia, oleh sebab itu rancangan arsitektur 
yang memenuhi kriteria pertimbangan tersebut disebut “Arsitektur ber Teknologi Hijau”. Adapun rujukan "Green Concept" yang digunakan sebagai alat ukur tingkatan Hijau diambil dari kriteria BREEAM (Building Research establishment's Environmental Assessment Method-Inggris-1990) diturunkan oleh GBCI (Green Building Council Indonesia) pada Greeship Home Checklist Assessment atau Sistim Penilaian Hijau untuk Kelompok Bangunan Hunian.

\section{METODOLOGI PENELITIAN}

\section{Teori Dasar}

Kajian tentang kearifan lokal Kampung Naga fokus pada pemanfaatan kembali kearifan lokal sebagai dasar rancangan. Merujuk pada ungkapan Haryanto bahwa Sekelompok pencakar langit yang mendeliniasikan garis langit ruang - ruang kota besar seperti Jakarta; Bentuk, Konstruksi serta Penggunaan bahan bangunan dengan teknologi modern memperlihatkan kemampuan teknologi menantang lingkungan alam yang ada.

Dengan adanya teknologi modern, maka kearifan lokal dianggap kuno, lambat dan tidak menarik. Sementara itu Kampung Naga memiliki kearifan lokal, tatacara dan ritual penggunaan material alam dan bahan bangunan sampai dengan ketentuanatau aturan yang harus dilakukan saat pelaksanaan pembangunan serta tatacara penanggulangan jika terjadi kesalahan prosedur (pelanggaran pelaksanaan).

Ditanah Parahyangan (masyarakat sunda) bangunan terdiri dari rumah (imah), tempat ibadah (surau atau masjid), balai pertemuan (bale dusun), lumbung padi (leuit),tempat menumbuk padi (saung lisung), kolam ikan (balong), kandang ternak, ruang terbuka (alun-alun), kebun, sawah dan sungai, berdekatan dengan lokasi mata pencaharian kebun,sawah, balong, alun - alun (tempat menjemur padi atau benda anyaman).

Adapun Parahyangan sebagai wilayah tataran tanah sunda sesuai ungkapan Hendi A dan Hafiz A. bahwa Keanekaragaman dan keindahan panorama alam yang terdapat di tanah Parahyangan memiliki arti tempat para dewa, tersusun diatas beranekaragam dataran tinggi-rendah. 


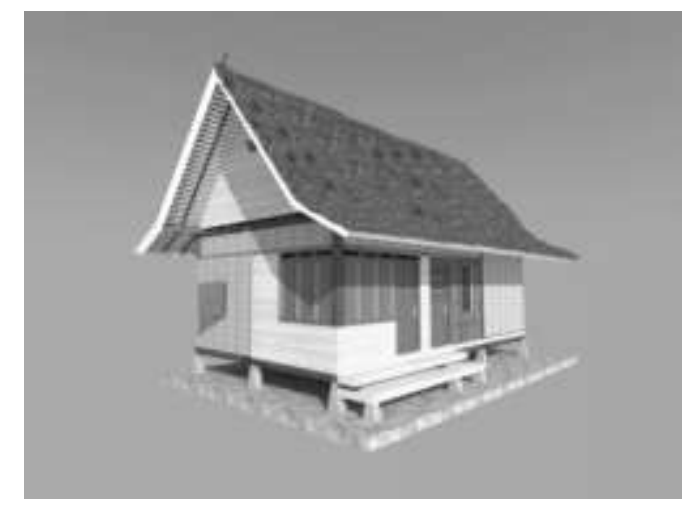

Gambar.2. Tipe Pemukiman Di Kampung Naga

(Sumber : Dokumentasi Pribadi)

\section{Topografi}

Letak Kampung Naga di tanah berbukit bersudut $45^{\circ}$, dan dataran rendah dibawah $8^{\circ}$ ditepi sungai Ciwulan. Maka jika merujuk pada ungkapan Heinz Frick (2006) bahwa rumah lerengan sangat menguntungkan karena rumah dan tanah berhubungan langsung,di sebut dengan rumah sengkedan dengan kemiringan topografi tanah sejajar garis konturnya, dan jika hampir seluruh lahan yang miring ditutupi dengan bangunan perumahan, maka lahan tersebut akan terasa padat, oleh karena itu kekuatan tanah bertambah kuat jika ditahan oleh dinding penahan tanah.Mempertimbangkan ungkapan diatas bangunan rumah sengkedan di lahan kemiringan $+45^{\circ}$ dan ketinggian bangunan tidak lebih dari satu lantai akan memperkuat garis kontur, seperti yang terjadi di Kampung Naga.



Gambar.3. Rumah Sengkedan

(Sumber : Frick, Heinz, tahun)

\section{Sanitasi}

Sanitasi merupakan pengetahuan untuk berkehidupan bersih, tertata atur dalam sebuah sistim pengarahan buangan padat dan air kotor, agar mencegah manusia bersentuhan langsung dengan kotoran atau limbah dan bahan berbahaya, sehingga diharapkan dapat menjaga dan meningkatkan 
kehidupan dan kesehatan manusia. Limbah atau material buangan berdampak pada masalah kesehatan (kotoran manusia atau binatang, sisa bahan buangan padat - sampah, serutan kayu atau bambu, air bahan buangan sisa mandi atau cucian). Drainase menurut Halim (2002) dibagi kedalam 4 jenis, yaitu : 1) menurut sejarah terbentuknya (drainase alamiah yang terbentuk dengan sendirinya tanpa campur tangan manusia, dan drainase buatan yang di bentuk berdasarkan analisis ilmu drainase untuk menentukan debit akibat hujan dan dimensi saluran);2) menurut letak saluran (drainase muka tanah, dan drainase bawah muka tanah); 3) menurut fungsi drainase (single purpose berfungsi mengalirkan satu jenis air buangan saja, sedangkan multy purpose berfungsi mengalirkan beberapa jenis buangan, baik secara bercampur maupun bergantian); 4) menurut konstruksi (saluran terbuka merupakan saluran air yang tidak dapat mengganggu kesehatan, dan saluran tertutup merupakan saluran untuk air kotor yang mengganggu kesehatan lingkungan). Sistem ini yang tanpa disadari telah ada sejak zaman dahulu, digunakan oleh masyarakat Kampung Naga sebagai sistem drainase.Drainase jika di kelola dengan baik, dapat menjaga kestabilan lingkungan dari pengaruh kerusakan akibat pencemaran, sehingga lingkungan dapat terjagadengan baik. Drainase berfungsi untuk : a) membuang air lebih; b) mengangkut limbah dan mencuci polusi dari daerah perkotaan; c) mengatur arah dan kecepatan aliran; d) mengatur elevasi muka air tanah; e) menjadi sumber daya air alternatif; f) didaerah perbukitan sistem drainase menjadi salah satu prasarana mencegah erosi dan gangguan stabilitas lereng.

\section{Pengelolaan Air}

Air merupakan sumber daya alam untuk menunjang keberlangsungan hidup dan aktivitas manusia. Air juga menjadi sumber penularan penyakit, sehingga sumber air maupun salurannya harus dikelola, dibedakan dan disesuaikan penggunaannya.

Sutrisno (1987) mengatakan bahwa :

1. Sumber air itu berasal dari: a). Air laut. Maka air ini tidak baik untuk minum, b). Air atmosfir (air hujan mengandung banyak kotoran dan tidak memiliki kadar mineral), c). Air permukaan (air rawa dan air sungai), dan d).Air tanah (air yang digunakan pada umumnya, yaitu air tanah dangkal, air tanah dalam, dan mata air).

2. Air bersih yang digunakan sebagai air minum ditinjau dari segi standar kualitas fisik air minum, yaitu berdasarkan : warna, bau, rasa, dan kekeruhan, untuk aktivitas lainnya tidak ada standar khusus yang mengikat. 
Penggunaan dan pemanfaatan air sebagai penunjang kehidupan dan aktivitas manusia, siklusnya sebagai berikut $\rightarrow$ penggunaan $\rightarrow$ air sisa pakai. Air merupakan sumber daya alam yang tidak dapat diperbaharui, sehinga pemanfaatan kembali menjadi solusi keberlangsungan dan kesejahteraan.

Dengan kata lain, perlu adanya suatu sistem pengelolaan air, seperti 3R (Reuse, Reduce, dan Recycle) yang berguna untuk pemanfaatan. Dengan teknik pengolahan yang tepat, kebutuhan air dapat terus terpenuhi. Adapun yang dimaksud Reuse atau guna ulang adalah penggunaan kembali sisa air yang dapat digunakan untuk fungsi yang sama atau fungsi lain. Reduce atau mengurangi adalah pengurangan penggunaaan air disegala hal yang berakibat adanya limbah. Recycle, (mendaur ulang) adalah pengolahan kembali dan pendaurulangan sisa air menjadi sesuatu barang atau produk yang bermanfaat. Cara yang dilakukan adalah penggunaan sisa buangan air (memanfaatkan kembali) pada suatu kegiatan tertentu. Selain itu, pemanfaatan air hujan dengan cara menampung dan menggunakannya kembali.

\section{Sumber daya alam}

Sumberdaya alam merupakan bahan pada lingkungan yang digunakan manusia untuk memenuhi keperluan hidupnya. Dengan kata lain sumber daya alam dapat diartikan sebagai sumber energi. Seperti ungkapan Prasasto (2005) bahwa Sumber daya alam energi adalah sumber energi dari segi ketersediaanya yang dibagi menjadi energi terbarui (renewable) dan tak-terbarui (non-renewable): a. Energi terbarui (renewable) merupakan energi yang relatif tidak pernah habis merugikan lingkungan, seperti energi matahari, angin dan air; b. Energi tak-terbarui (non-renewable) merupakan energi yang dapat habis dan tidak dapat diperbarui, seperti minyak, batu bara, dan gas alam.

\section{Konsep dan Cara Membangun}

Konsep dan metoda konstruksi dibagi menjadi dua, yaitu tradisional dan modern. Keduanya memiliki kelebihan dan kelemahan terkait kecepatan membangun, pembiayaan, keterlibatan manusia, penggunaan sumber daya alam, dampak terhadap lingkungan. (Karyono 2010) menyatakan bahwa a. Pada konsep tradisioanal, keterbatasan ilmu pengetahuan dan teknologi akan membatasi kemampuan manusia mengubah alam dan penggunaan sumberdaya alam. Kepercayaan terhadap kekuatan alam yang bersifat abstrak seperti sungai, pohon besar, batu dan lainlain.Pemanfaatan alam dibatasi, kelestarian di jaga tanpa melakukan perusakan. Konsep tersebut menjaga eksploitasi alam tidak terjadi, bangunan cenderung menyatu dengan alam, kualitas sumber daya ( air, tanah, udara, iklim tetap terjaga) dan lingkungan. 


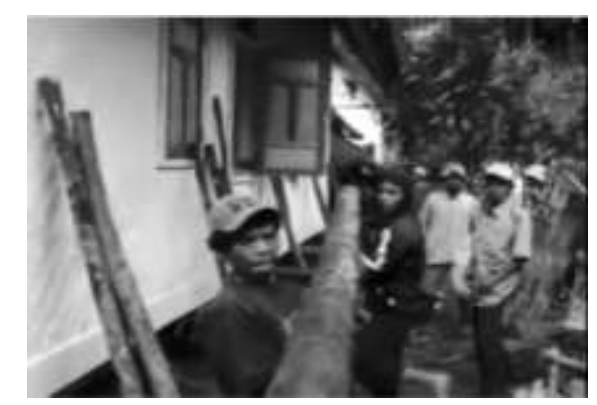

Gambar.4. Pembangunan Hunian Di Kampung Naga Digunakan Konsep Tradisional Agar Tidak Menghasilkan Emisi Co2.

(Sumber :www.google.co.id)

b. Konsep Modern adalah memberikan kesadaran bagi masyarakat kota sehingga timbul pemikiran dengan menciptakan teknologi ramah lingkungan, namun secara proses tetap terjadi kerusakan lingkungan walau tidak signifikan, namun demikianhal tersebut demi kemajuan kehidupan.

Pembangunan modern cenderung lebih mengeksploitasi teknologi, energi dan sumberdaya alam tanpa memperhitungkan dampak negatifnya pada lingkungan.

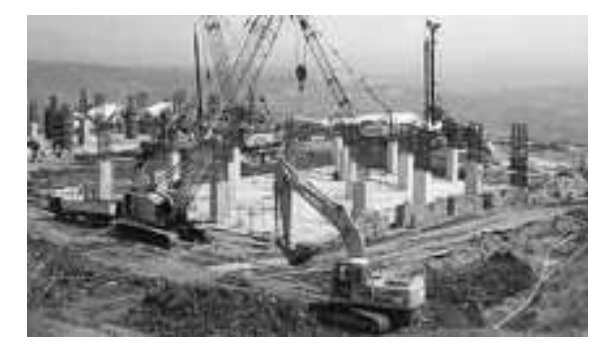

Gambar.5. Pembangunan Modern Pembangunan Cenderung Merubah Fisik Alam Dari Pada Melestarikan.

(Sumber :www.google.co.id)

\section{Arsitektur Hijau}

Bermacam - macam pengertian Arsitektur Hijau dikemukakan para pemerhati lingkungan binaan. Pengertian-pengertian tersebut sejatinya merujuk pada hal yang sama yaitu bahwa Arsitektur Hijau adalah lingkungan binaan yang selaras dan menyatu dengan alam sehingga dapat menggunakan sumberdaya secara efisien, tidak membebani serta tidak menyebabkan turunnya kualitas lingkungan dengan tetap memenuhi prinsip kenyamanan, keselamatan, keamanan, dan kesehatan.

Berikut ini merupakan dua definisi Arsitektur Hijau, dilihat dari sudut pandang yang berbeda. Pertama, menurut GBCI (Green Building Council Indonesia, 2010), bahwa bangunan hijau (green 
building) adalah bangunan baru yang direncanakan dan dilaksanakan atau bangunan sudah terbangun yang dioperasikan dengan memperhatikan faktor-faktor lingkungan /ekosistem dan memenuhi kinerja: bijak guna lahan, hemat air, hemat energi, hemat bahan kurangi limbah, dan kualitas udara dalam ruangan. Karyono (2010) menjelaskan bahwa arsitektur hijau merupakan suatu rancangan lingkungan binaan, kawasan dan bangunan yang mampu beradaptasi dengan lingkungan, dalam memenuhi kriteria hemat energi dalam menggunakan sumber daya alam yang tidak dapat menimbulkan dampak negatif.

\section{Manfaat Arsitektur Hijau}

Penerapan konsep arsitektur hijau banyak memberikan dampak positif bukan hanya pada lingkungan tetang sumber daya alam, namun juga dapat memberikan manfaat baik dalam ekonomi, maupun pengguna bangunan itu sendiri. Seperti yang diutarakan "The US Environmental Protection Agency "dalam buku The Green Building Handbook mendefinisikan manfaat dari bangunan hijau dalam tiga kategori utama, yaitu :

1. Manfaat Lingkungan: bangunan hijau melestarikan sumber daya alam, meningkatkan kualitas udara dan air, dan mengurangi limbah.

2. Manfaat Ekonomi: bangunan hijau mengurangi biaya modal dan operasional, meningkatkan nilai properti, dan meningkatkan produktivitas pekerja.

3. Kesehatan dan Masyarakat. Manfaat: bangunan hijau meningkatkan kesehatan, kesejahteraan, dan kualitas hidup bagi penghuni maupun masyarakat sekitarnya.

\section{Sertifikasi Arsitektur Hijau}

Indonesia merupakan negara yang ikut berpartisipasi dalam menangani masalah lingkungan dunia. Hal ini dibuktikan dengan aktifnya Indonesia dalam berbagai konferensi tingkat dunia dan yang terakhir sebagai penyelenggara untuk konferensi masalah perubahan iklim di Bali pada tahun. Oleh karena itu Indonesia memiliki badan atau organisasi yang menangani pembangunan ramah lingkungan. Lembaga tersebut diberi nama Lembaga Konsil Bangunan Hijau Indonesia atau Green Building Council Indonesia adalah yang merupakan lembaga mandiri (non government) dan nirlaba (non profit) yang berkomitmen penuh terhadap pendidikan masyarakat dalam mengaplikasikan praktik-praktik terbaik lingkungan dan memfasilitasi transformasi industri bangunan global yang berkelanjutan. 
Lembaga Konsil Bangunan Hijau Indonesia atau Green Building Council Indonesia nantinya yang akan memberikan penilaian terhadap setiap gedung yang memiliki konsep hijau berdasarkan tingkatan seberapa besar penerapan hijau pada suatu gedung itu di berlakukan, dan diuji berdasarkan standar yang telah dibuat.

\section{Sistem Rating}

Tingkat kehijauan suatu bangunan kawasan dapat diposisikan padalevel yang dapat dimengerti dan diukur oleh suatu acuan tertentu. Maka diperlukan alat ukur dan tolok ukur untuk mengukur level kehijauan suatu objek.

Sistim rating adalah suatu alat berisi butir-butir dari aspek penilaian yang disebut rating dan setiap butir rating mempunyai nilai (credit point/poin nilai) Apabila suatu bangunan berhasil melaksanakan butir rating, maka bangunan itu akan mendapatkan poin nilai dari butir tersebut. Bila jumlah semua point nilai yang berhasil dikumpulkan mencapai suatu jumlah yang ditentukan, maka bangunan tersebut dapat disertifikasi untuk tingkat sertifikasi tertentu. Namun sebelum mencapai tahap penilaian rating terlebih dahulu dilakukan pengkajian bangunan untuk pemenuhan persyaratan awal penilaian (eligibilitas).

Greenship merupakan standar bangunan hijau yang dikembangkan oleh Lembaga Konsul Bangunan Hijau Indonesia atau Green Building Council Indonesia (GBCI).

Standar yang ingin dicapai dalam penerapan Greenship adalah upaya untuk mewujudkan suatu konsep green building (bangunan hijau) yang ramah lingkungan sejak dicanangkannya tahapan perencanaan sampai dengan operasional. Sistem penilaian itu sendiri dibedakan sesuai karakter bangunan (contoh:greenship home asessment dan greenship new building asessment)

Adapun sistem penilaiannya(di Indonesia “Green Building Council of Indonesia" (GBCI) sebagai Pedoman untuk Rumah Tinggal bukan Gedung (Greenship Home Checklist Assessment) dibagi berdasarkan enam kategori, yaitu: Tepat guna lahan; konservasi dan efisiensi energi; konservasi air; siklus dan sumber material; kesehatan dan kenyamanan dalam ruang; dan manajemen lingkungan bangunan.

Isu Konsep Hijau terdiri dari 10 aspek tolok ukur, yaitu: manajemen; kenyamanan dan kesehatan; energi; transportasi; air; material; limbah; penggunaan lahan dan lingkungan; polusi dan inovasi, 
Rujukan dari GBCI sudah mengandung isyu konsep hijau, karena itu langsung diujikan pada karakter permukiman Kampung Naga.

\section{Metodologi}

Dimulai dengan pengumpulan data primer dan sekunder, kemudian dikaji, diklasifikasi dalam 7 isu (Pengelolaan air, Sanitasi, Kemiringan Lahan, Pengelolaan sumber daya alam, Pendekatan Teknologi Hijau, Struktur dan Material/bahan bangunan) kemudian pada teori tentang teknologi bangunan, penghawaan, lingkungan, ilmu bahan, dan ilmu arsitektur yang dipertimbangkan dengan ketentuan atau isu pada Greenship Home Dari GBCI (Green Bulding Council Indonesia) lalu disimpulkan dan dideskripsikan sebagai hasil kajian, dan dijadikan panduan perancangan.

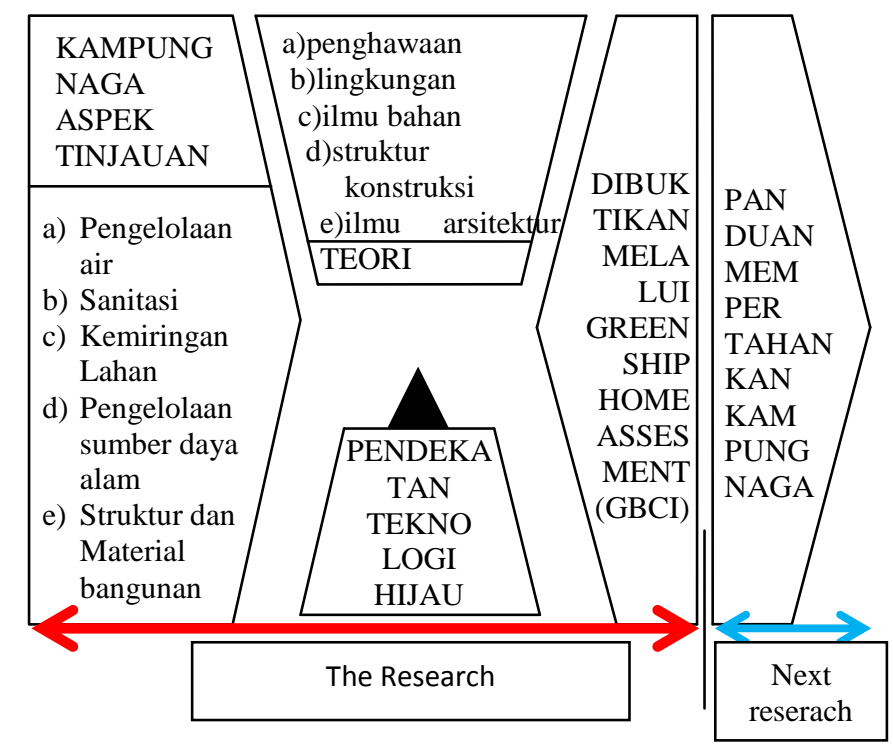

Gambar 6. Diagram Metode Pembahasan

\section{HASIL DAN PEMBAHASAN}

Merupakan hasil kajian atau analisa sesuai dengan Greenship Home Asessment, dari GBCI untuk kategori rumah sederahana. 


\subsection{KATEGORI TEPAT GUNA LAHAN ( APPROPRIATE SITE DEVELOPMENT )}

\subsubsection{Area Hijau (Green Area)}

Di Kampung Naga, unit rumah hampir tidak memiliki lahan vegetasi, warga kampung naga sangat menjaga lingkungannya dengan mitos dan peraturan adat.

\subsubsection{Infrastruktur Pendukung}

Prasarana umum Kampung Naga hanya ada jaringan jalan, jaringan drainase untuk air hujan, sistem pembuangan sampah, jalur pejalan kaki di kawasan, STP kawasan yg berbentuk kolam.

\subsubsection{Aksesibilitas Komunitas}

Dilengkapi dengan fasilitas umum bagi kegiatan masyarakat; yaitu masjid, gedung serbaguna, warung.

\subsubsection{Transportasi umum}

Bagi penghuni dan wisatawan tidak adafasilitas kendaraan, kecuali berjalan kaki.

\subsubsection{Penanganan air limpasan hujan}

Drainase dibentuk dari kontur tanah sehingga air hujan langsung dialirkan menuju balong.

\subsection{KATEGORIEFISIENSI DAN KONSERVASI ENERGI （ ENERGY EFFICIENCY \& CONSERVATION )}

\subsubsection{Sub Meteran (Sub-Metering)}

Di Kampung Naga, aliran listrik tidak di perbolehkan,sebagai sarana informasi (radio) menggunakan aki yang harus diisi ulang.

\subsubsection{Pencahayaan Buatan}

Penggunaan petromaks, lampu tempel dan cahaya bulan sebagai alat pencahayaan.

\subsubsection{Pengkondisian udara}

Penghawaan alami di dapat dari bukaan jendela dan celah-celah dari bilik bambu.

\subsubsection{Reduksi panas}

Material bangunan Kampung Naga menggunakan kayu pada bagian struktur, dinding dan lantainya, menggunakan anyaman bambu untuk dinding dan plafon, bagian atapnya menggunakan ijuk, yang dapat mereduksi panas. 


\subsubsection{Sumber energi terbarukan}

Warga Kampung Naga tidak memiliki sumber energi terbarukan.

\subsection{KATEGORIKONSERVASI AIR ( WATER CONSERVATION )}

\subsubsection{Alat keluaran hemat air}

Warga Kampung Naga memanfaatkan aliran air dari Sungai Ciwulan dan pegunungan.

\subsubsection{Penampungan Air hujan}

Penampungan air hujan dialirkan pada balong, jika penuh secara otomatis dialirkan ke Sungai Ciwulan.

\subsubsection{Irigasi hemat air}

Persawahan dan perkebunan memanfaatkan air hujan dan air Sungai Ciwulan.

\subsection{KATEGORISUMBER DAN DAUR MATERIAL ( MATERIAL RESOURCE AND CYCLE )}

\subsubsection{Refrigeran bukan perusak ozon}

Pada Kampung Naga tidak terdapat AC, hanya menggunakan penghawaan alami

\subsubsection{Penggunaan material lama}

Pergantian material pada rumah Kampung Naga biasanya dilakukan pada bagian atap yaitu material ijuk yang sering dilakukan pada periode tertentu.

\subsubsection{Material dari sumber yang ramah lingkungan}

Penggunaan bahan alami seperti kayu, ijuk bambu dan batu, sebagai bahan daur ulang dari daerah sekitar.

\subsubsection{Material dengan proses produksi ramah lingkungan}

Pembangunan yang dilakukan secara tradisional tanpa bantuan mesin.

\subsubsection{Kayu Bersertifikat}

Kayu yang digunakan berasaldari daerah setempat dari hutan sekitarnya.

\subsubsection{Material prefab}

Bahan alami yang digunakan tidak menimbulkan sampah yang sulit didaur ulang. 


\subsubsection{Material lokal}

Seluruh material bangunan yang digunakan di Kampung Naga didapatkan dari area setempat kecuali kapur sebagai material higenitas.

\subsubsection{Pemilahan sampah}

Pemilahan sampah antara organik (sebagai umpan ikan) dan non-organik (dibakar lalu dibuang ke sungai), dipisahkan secara manual.

\subsection{KATEGORI KESEHATAN DAN KENYAMANAN DALAM RUANG ( INDOOR HEALTH AND COMFORT )}

\subsubsection{Sirkulasi udara bersih}

Pada rumah Kampung Naga proses sirkulasi udara melalui ventilasi silang dengan dua bukaan jendela.

\subsubsection{Minimalisasi sumber polutan}

Tidak menggunakan cat sehingga kadar VOC tidak ada karena digunakan kapur untuk warna dinding.

\subsubsection{Tingkat akustik}

Pengguanaan material kayu sebagai peredam suara, dikarenakan material kayu memiliki tekstur berpori dan tidak memantulkan suara.

\subsection{KATEGORI MANAJEMEN LINGKUNGAN BANGUNAN ( BUILDING ENVIRONMENT MANAGEMENT )}

\subsubsection{Aktivitas ramah lingkungan}

Adanya peraturan adat yang membatasi warga untuk menjaga dan memelihara lingkungan.

\subsubsection{Panduan bangunan rumah}

Warga mengikuti ajaran nenek moyang dalam melaksanan kegiatan kesehariannya.

\subsubsection{Keamanan}

Keamanan dilakukan secara sistem tradisional dengan kebersamaan warganya yang saling gotong royong untuk menjaga. 


\subsubsection{Desain dan konstruksi berkelanjutan}

Pembangunan melibatkan seluruh masyarakat kampung naga, sebelum proses pembangunan dilakukan musyawarah terlebih dahulu.

\subsubsection{Inovasi}

Mempertahankan aturan adat untuk tetap menjaga lingkungan dan tidak terbawa oleh arus modernisasi.

\subsubsection{Desain rumah tumbuh}

Rumah di Kampung Naga jumlahnya selalu dipertahankan, yaitu tidak boleh kurang dan lebih dari 118 bangunan, sehingga ketika kapasitas melebihi diharuskan membangun diluar kampung.

\section{KESIMPULAN}

Dari penelitian ini, disimpulkan arsitektur vernakular merupakan turunan dari nenek moyang, secara alamiah telah mengadaptasi "Teknologi Hijau" pada beberapa siklus berkehidupan dan memanfaatkan sumber daya alam. Sistem pembangunan menerapkan sistem daur ulang untuk mempertahankan sumber daya alam.

Penerapan "Teknologi Hijau" dibina secara arif dan bijak, seperti reboisasi, pemanfaatan dan pengoptimalan ruang terbuka hijau, sehingga keberlangsungan makhluk hidup dan lingkungan akan terus terjaga.

\section{DAFTAR PUSTAKA}

Anwar, Hendi (2013). Rumah Etnik Sunda. Depok : Griya Kreasi.

B. Setiawan, Haryadi (2010). Arsitektur, Lingkungan dan Perilaku- Pengantar ke Teori, Metodologi dan Aplikasi. Yogyakarta : Gadjah Mada University Press.

Frick, Heinz (2006). Arsitektur Ekologis - Konsep Arsitektur Ekologis di Iklim Tropis, Penghijauan Kota dan Kota Ekologis, serta Energi Terbarukan. Yogyakarta : Kanisius.

Hasmar, Halim, H.A (2002).Drainasi Perkotaan. Yogyakarta: UII Press.

Karyono, Harso. T (2010).Green Architecture : Pengantar Pemahaman Arsitektur Hijau di Indonesia. Jakarta : Rajawali Pers.

Mulyanto, H.R (2013). Penataan Drainase Perkotaan. Yogyakarta : Graha Ilmu. 
Salura, Purnama (2007). Menelusuri Arsitektur Masyarakat Sunda. Bandung : Cipta Sastra Salura. Sutrisno, Totok (1987). Teknologi Penyediaan Air Bersih. Jakarta : Bina Aksara.

Raditya Permana (2007).“Sistem Pengelolaan Air Pada Masyarakat Kampung Naga”,Percik Media Informasi Air Minum dan Penyehatan Lingkungan.Vol. XVIII.No. ISSN 1829-5967, hal. 14, Juli, 2007. 